\title{
A Cost Analysis of Mobile and Stationary Pellet Mills for Mitigating Wildfire Costs
}

\author{
Ryan Jacobson'1, Shahab Sokhansanj1, Dominik Roeser', Jason Hansen², Bhushan Gopaluni', \\ Xiaotao Bi ${ }^{1}$
}

${ }^{1}$ University of British Columbia, Vancouver, Canada

${ }^{2}$ Idaho National Lab, Idaho Falls, USA

Email: Shahab.sokhansanj@ubc.ca

How to cite this paper: Jacobson, R., Sokhansanj, S., Roeser, D., Hansen, J., Gopaluni, B. and Bi, X.T. (2021) A Cost Analysis of Mobile and Stationary Pellet Mills for Mitigating Wildfire Costs. Journal of Sustainable Bioenergy Systems, 11, 131-143. https://doi.org/10.4236/jsbs.2021.113010

Received: June 29, 2021

Accepted: September 20, 2021

Published: September 23, 2021

Copyright $\odot 2021$ by author(s) and Scientific Research Publishing Inc. This work is licensed under the Creative Commons Attribution International License (CC BY 4.0).

http://creativecommons.org/licenses/by/4.0/

\begin{abstract}
A comparison of traditional and mobile wood pellet mills found that mobile systems had higher production costs. Wildfire suppression costs have consistently exceeded British Columbia's budget set for such activities. Pelletization of excess wood for bioenergy applications has been proposed as a possible method of reducing the overall costs of fighting wildfires. In this study, a traditional pellet mill produces wood pellets from new, marginal feedstocks for $\$ 182.24 \pm 24.47$ tonne $^{-1}$ and a mobile pellet production system produces wood pellets for $\$ 402.71 \pm 24.18$ tonne $^{-1}$. The traditional pellet mill produces 90,000 tonnes. $\mathrm{yr}^{-1}$ with harvest residues being collected in the forest, transported to the pellet mill, dried, chipped, pelletized and then stored. The mobile system collects harvest residues from the forest, transports them to the forest landing where the trailer-mounted mobile pellet system is established and is then ground, pelletized and dried if needed. The mobile system uses a novel high moisture pelletization system and harvest residues to heat the biomass dryer used in the system. The mobile pellet system requires 22 systems to produce 90,000 tonnes $\cdot \mathrm{yr}^{-1}$ and each system should relocate 9 times in a year to minimize production costs related to feedstock quality and scarcity. These mobile pellet systems can allow increased forest management in forest areas at high risk for wildfires and reduce the cost of suppressing wildfires in treated areas.
\end{abstract}

\section{Keywords}

Bioenergy, Harvest Residues, Mobile Pelletization, High Moisture

\section{Introduction}

Mobile pellet mills improve overall transportation costs by shipping wood pellets 
with higher bulk densities than the whole wood or wood chips. The smaller production capacity and mobility will encourage the pellet mills to relocate when cheaper feedstocks have been exhausted in an area. Figure 1 shows the basic configuration of a mobile pellet mill, with small feedstock storage, pellet press, cooler, and sieve.

With mobile systems, economies of scale are minimal because production volumes are small to minimize logistics and the area footprint of the production equipment. To scale up production with the mobile system, entirely new systems must be created; each system has a limited ability to be modified for larger production due to the space restrictions on a trailer. Each mobile system in our analysis produces 4056 tonnes. $\mathrm{yr}^{-1}$, requiring 22 systems to produce 89,232 tonnes of wood pellets each year. Production costs are generally too high to be considered for large-scale commercial usage.

The mobile pellet mill analyzed here is not designed to compete with current pellet mills but to open new feedstock sources to harvesting and management in a cost-effective manner. Current pellet mills have already found sustainable sources of feedstock that will support their operations unless a massive disturbance occurs in the area. The mobile systems described in this analysis could provide a supplemental supply of wood pellets in the event of such a disaster. The mobile pellet system assessed here uses only harvest residues from timber harvesting operations.

The following sections will discuss the analysis of the mobile and traditional pelletization systems. The traditional pellet mill produces 90,000 tonnes of wood pellets each year, while the mobile pellet mill produces 4056 tonnes of wood

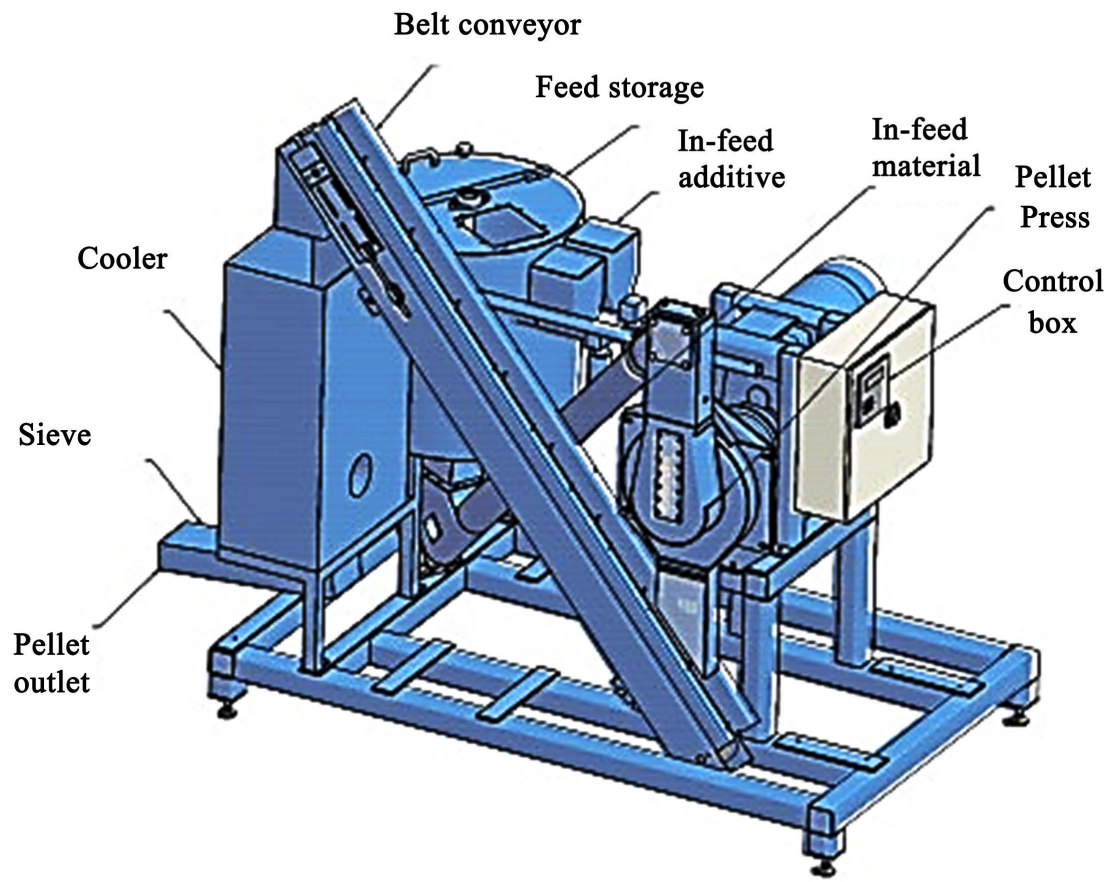

Figure 1. A diagram of the Sweden Power Chippers AB PP150 model mobile pellet press [1]. 
pellet per year. The traditional system collects harvest residues and transports them $70 \mathrm{~km}$ to Prince George, British Columbia, for pelletization. In the mobile system, the harvest residues are collected, comminuted, and transported $2 \mathrm{~km}$ for pelletization, and the wood pellets are transported $70 \mathrm{~km}$ to the city of Prince George. Figure 2 shows the process flow of the traditional pellet mill analyzed here (Figure 2(a)) and the mobile pellet mill (Figure 2(b)) and a combination of the two systems (Figure 2(c)).

High moisture pelletization is a new method for creating pellets that can reduce dryer energy use and overall production costs [2]. In high moisture pelletization processes, the feedstock is ground and enters the pellet die with a moisture content of $30 \%$ - 36\% wet basis (w.b.) [2] [3]. Drying can account for $70 \%$ of energy consumption in a pelletization process, allowing reductions in drying energy to have large impact on reducing production costs [3]. This process is used in the mobile pelletization process discussed in this section, allowing naturally dried residues to enter the pellet mill without drying and only requiring minimal drying after pelletization. Reference [4] found that feedstock moisture in pine and spruce residues could decrease $40 \%-60 \%$ over eight months in Sweden, Scotland and northern Italy. If feedstock behaves in a similar manner in the interior of British Columbia, moisture content can reach the upper limits of high moisture pelletization.

The average pellet mill in British Columbia produces 185,000 tonnes $\cdot \mathrm{yr}^{-1}$, and the Prince George region has several operational pellet mills that use feedstock from the nearby forests [5] [6]. A 90,000-tonne pellet mill was selected for assessment as the traditional pellet mill option as it is representing a possible option for a new pellet mill in the area based on available feedstock. Wood pellets produced in North America sell for $\$ 180$ - 220 tonne $^{-1}$, with estimates of production costs being $\$ 100-140$ tonne $^{-1}$ [7]. An average pellet mill in British

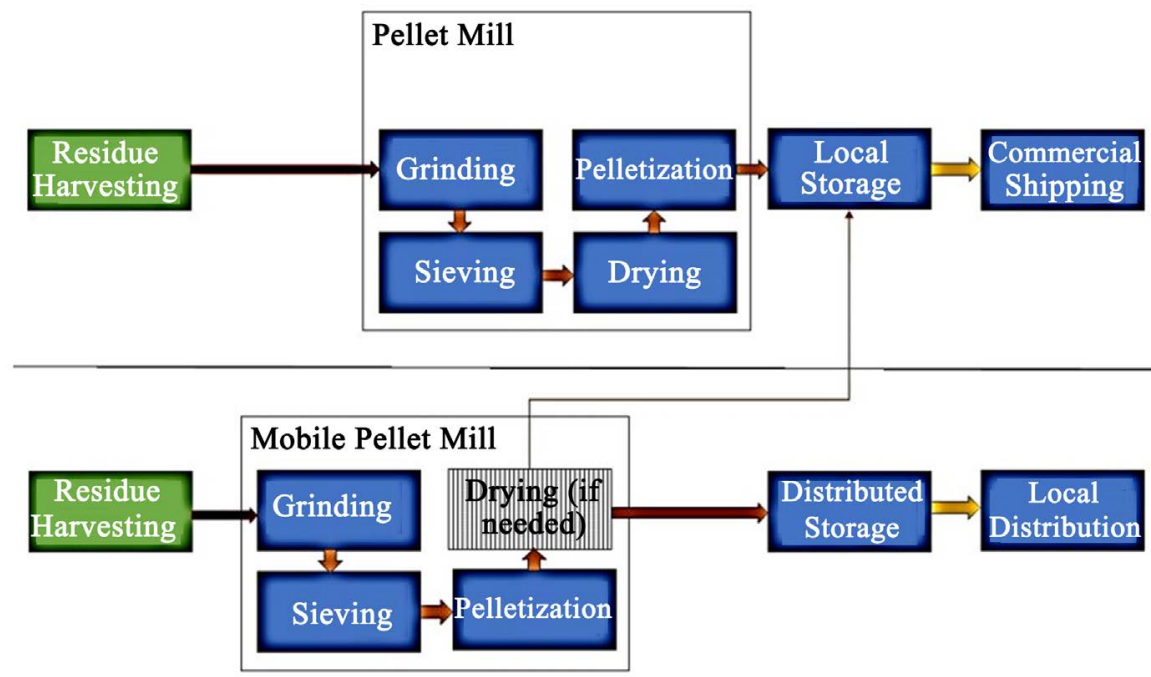

Figure 2. The process flow for a (a) traditional pellet mill and (b) a mobile pellet mill, and (c) a mobile pellet mill that sends wood pellets to a currently existing traditional pellet mill storage silo, Distributed production using traditional storage. 
Columbia employs ten employees full-time, with an average annual wage of $\$ 25,000$. Each pellet mill has a grinder, dryer, pellet die, and storage silos. Balancing the increasing costs of feedstock with the economies of scale is critical to determining the sizing of the pellet mill [8]. Feedstock costs rise with increased demand, but equipment and operational costs decrease due to increases in production outpacing increases in costs for larger equipment and more employees [9].

The mobile system assessed here is mounted on a truck-towable trailer and includes a chipper, dryer, conveying and screening systems, and a pellet die. There are two storage scenarios in the analysis, one with in-situ storage in the forest. In the second, the produced wood pellets are intermixed with traditionally produced wood pellets in an existing pellet silo. An additional scenario with no drying due to feedstock having already reached usable moisture contents is analyzed. As the system is mobile, there is no land purchase cost. A generator using diesel can power all the equipment, or the system can be attached to an existing power grid that would supply cheaper fuel costs. Figure 2(b) and Figure 2(c) show the process flows for the two mobile pelletization scenarios.

In-situ storage allows production to continue without a final purchaser having been located. Building storage can be very expensive depending on the type of storage desired. In this mobile system, it was determined that semi-permanent structures or temporary tarpaulin was most applicable to the designs of the system. Simple tarpaulin costs $\$ 0.25 \mathrm{~m}^{-2}$ and is the cheapest option but provides pellets with the least protection from the elements, microbial and fauna, or wildfires [10]. Bins cost roughly $\$ 35.31 \mathrm{~m}^{-3}$ and are similar to raised agricultural bins that are located field-side, which allows trucks to drive under or beside to have material gravity fed into the hauling container and protect from precipitation, some humidity and some animal activity [9]. The next level of protection is tubular tarpaulin, similar in price to simple tarpaulin but requires more material to enclose the wood pellets inside. The next level of protection is a shed-like structure that provides a roof to shield the wood pellets from the elements; this requires some engineering to ensure wood pellets can be stored under the roof without collapsing the supports. The next level of protection is a raised metal bin that allows gravity feeding of stored pellets into a truck that drives underneath, as is done field-side in some agricultural operations. Raised bins require engineering and potentially some land payments as the storage bin are semi-permanent. These bins provide good protection from the elements and fire protection and keep the pellets raised away from fauna like mice that can damage the wood pellets. A silo is the highest level of protection for wood pellets and is the most expensive. The expenses of constructing a silo would require the structure to be at a location for long periods, if not permanently.

In the mobile pellet mill analysis, using a biomass-fueled dryer is possible because of the low cost of harvest residues in the immediate area of the dryer. In traditional pellet production, natural gas is combusted to provide heat energy to evaporate water from comminuted harvest residues, which are then pelletized. In the mobile system analyzed here, the harvest residues are collected, comminuted, 
pelletized, and then dried to reach the ideal pellet moisture content for storage. The compression of the pelletization process forces water from the material and the heat from the friction produced also removes water from the material, reducing the overall energy needed to dry the wood pellets later [11]. In a traditional pellet mill, natural gas would be the less expensive option because harvest residues would need to be transported to the mill, however, the minimal feedstock transportation distances in the mobile pellet mill scenario allow biomass to be a plentiful, cheap fuel source.

\section{Methods}

To compare a traditional and mobile wood pellet mill, a framework was designed in Microsoft Excel to assess the production costs and labor required for both systems to operate at full capacity. The system assesses the costs to collect harvest residues, labor, energy, maintenance and repair, storage, transportation, and any loan payments. The traditional pellet mill requires material to be harvested and transported $70 \mathrm{~km}$ to the pellet mill, where it is comminuted, dried, pelletized and stored for 45 days, with the storage silo having a capacity of 11,000 tonnes. The mobile pellet mill uses a chipper-forwarder to collect and comminute harvest residues and transport the chips to a trailer mounted pelletization process located at the forest landing, where the chips are fed into a hammer mill for final grinding, pelletized at a high moisture content, then dried after being pelletized if needed. Two types of storage are considered in the mobile system, in-forest storage using raised bins akin to grain bins or transportation to Prince George $70 \mathrm{~km}$ away for storage in existing pellet storage.

The traditional pellet mill requires 112,500 Bone Dry Tonnes (BDT) of harvest residues to reach full production capacity. Nine harvesting crews are needed to provide the harvest residues, with an hourly harvesting rate of 4.2 green tonnes or approximately $10 \mathrm{~m}^{3} \cdot \mathrm{hr}^{-1}$.

Harvest residues have a bulk density of $0.17 \pm 0.02$ tonne $\cdot \mathrm{m}^{-3}$ and a moisture content of $40 \% \pm 8 \%$. Table 1 shows the traditional pellet mill's feedstock variables of interest. The feedstock is transported an average distance of $79 \pm 11$ $\mathrm{km}$ at a cost of $\$ 0.20$ tonne $\mathrm{e}^{-1} \cdot \mathrm{km}^{-1}$. Harvesting crews operate 50 weeks per year, 160 hours per week. There are two twelve-hour shifts per day. Residue harvesting is assumed to be half the productivity rate of standing timber harvesting but

Table 1. Feedstock harvesting parameters.

\begin{tabular}{cc}
\hline Feedstock harvesting parameters & Parameters of interest \\
\cline { 2 - 2 } Feedstock required (Bone Dry Tonnes) & Average \\
Harvesting crews (count) & 112,500 \\
Harvest rate (green tonnes $\cdot \mathrm{hr}^{-1}$ ) & 9 \\
Bulk density (tonnes $\cdot \mathrm{m}^{-3}$ ) & 4.2 \\
Moisture content (\% wet basis) & $0.17 \pm 0.02$ \\
\hline
\end{tabular}


less expensive because the harvesting of the tree is already paid for by the timber harvester. Each crew produces $212 \mathrm{~m}^{3} \cdot \mathrm{hr}^{-1}$ or about 31.8 green tonnes $\cdot \mathrm{hr}^{-1}$ [2] [3] [5]. Feedstock is transported $70 \mathrm{~km}$ from the landing to the pellet mill [6] [8]. Transportation costs account for $\$ 14.00$ tonne $^{-1}$ of pellets produced.

Inside the traditional pellet mill, the feedstock is converted to wood pellets at an $80 \%$ rate. The losses in the feedstock come from material loss in comminution and contaminated material that is unusable for pellet production. There are 9 laborer positions employed in the pellet mill, with an average wage of $\$ 20 \mathrm{hr}^{-1}$ and one manager position earning $\$ 60,000 \mathrm{yr}^{-1}$. The pellet mill operates $90 \%$ of the year, or $7740 \mathrm{hr} \cdot \mathrm{yr}^{-1}$. Capital costs in the system total $\$ 11.25$ million and no loan is used to pay for the capital. Constructing a storage silo costs $\$ 35.31 \mathrm{~m}^{-3}$ to construct and a capacity of 11,000 tonnes is needed with a residence time of 45 days [12]. Table 2 shows the variables of interest in the production process. This system uses a self-propelled mobile chipper to collect and chip the harvest residues that are piled at the roadside. Reference [9] found that a forwarder mounted mobile chipper cost $\$ 30.19$ green tonne ${ }^{-1}$ to chip and forward roadside harvest residues. The study found fuel costs for operating a mobile chipper at $\$ 46.92$ Performed Machine Hour $^{-1}(\mathrm{PMH})$ and other operating costs being $\$ 475.24$ $\mathrm{PMH}^{-1}$.

The mobile pellet mill is supplied with harvest residues using a chipper-forwarder, a machine with a chipper and storage bin mounted behind the operator's cab. The pellet mill in this process is mounted on a trailer with a Hammermill before the pellet die, and a biomass fueled dryer mounted after the pellet die. Each machine requires 48,286 green $\mathrm{m}^{3}$ of feedstock each year for full production of 4056 tonnes of wood pellets. The mobile system can relocate when feedstock becomes scarce in an area, with the average being 9 times per year and requires 40 hours for relocation and set up at the new location. Relocations allow the mobile system to access feedstock that is both close to the pellet mill location

Table 2. Production parameters for the traditional pellet mill.

\begin{tabular}{cc}
\hline Traditional pellet mill production parameters & Parameters of interest \\
\cline { 2 - 2 } Feedstock delivered (Bone Dry Tonnes) & Average \\
Conversion ratio & 112,500 \\
Laborer employees & 0.80 \\
Laborer wage $\left(\$ \cdot \mathrm{yr}^{-1}\right)$ & 9 \\
Manager employees & 20 \\
Manager salary $\left(\$ \cdot \mathrm{yr}^{-1}\right)$ & 1 \\
Operating hours $\left(\mathrm{hr}^{-1} \mathrm{yr}^{-1}\right)$ & 60,000 \\
Storage cost $\left(\$ \cdot \mathrm{m}^{-3}\right)$ & 7740 \\
Storage capacity (tonnes) & 35.31 \\
Storage residence time (days) & 11,096 \\
\hline
\end{tabular}


and low in moisture content to minimize drying costs. Cut blocks in British Columbia's interior forests are limited to 60 hectares, requiring locations for the mobile system to be between two nearby cut blocks, or additional relocations will be required to operate at full capacity [13] [14] [15]. Figure 3 shows the marginal cost of relocations for the mobile pellet mill.

The chipped harvest residues are delivered to the mobile pellet mill located at a forest landing near the residues source and fed directly into the final comminution process on the trailer containing the pellet mill. With average residues densities per hectare province-wide being approximately $113 \mathrm{~m}^{3} \cdot \mathrm{ha}^{-1}, 329 \mathrm{hec}-$ tares of harvested timberland residues provide enough feedstock for one year of operation of one mobile pellet system. The minimized relocation costs happen when 8 locations are used each year.

Once properly sized for pelletization, the material is fed into the pellet die and then the formed pellets are dried when needed. When the pellets are properly conditioned for storage, two options are considered, transportation $70 \mathrm{~km}$ to already existing storage or construction of raised storage bins at the production site that will hold the pellets until a buyer can be found. The raised storage bins each have a capacity of 32 tonnes.

A Monte Carlo simulation was developed to determine the averages and standard deviations of high impact variables. The variables that were assigned statistical distributions were identified using a manual sensitivity analysis. The Monte Carlo simulation used 600 runs to identify the production costs of the traditional and mobile pellet mills. Table 3 shows the averages and standard deviations of the selected variables in the analysis.

\section{Results}

Table 4 compares the production costs and standard deviations of the mobile and traditional pellet mills. Production costs in the traditional pellet mill totaled

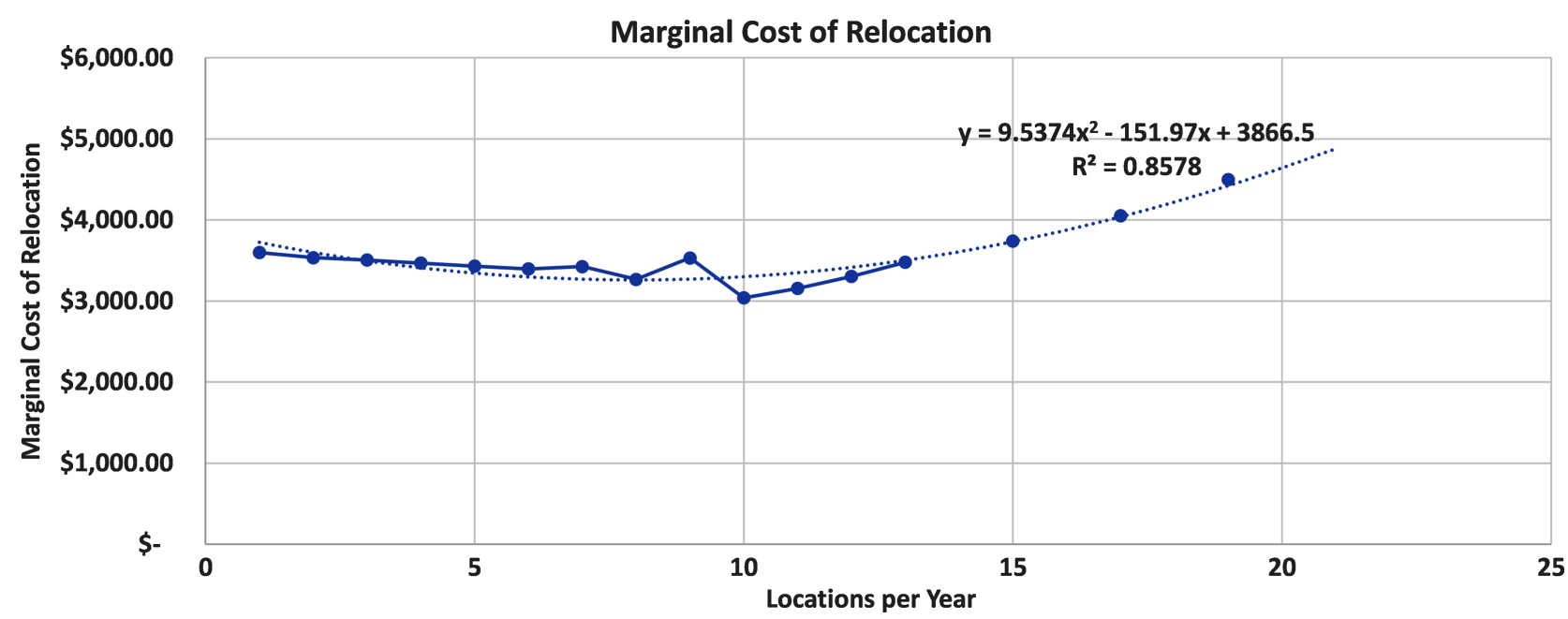

Figure 3. The marginal cost curve for relocating the mobile pellet mill. The minimal cost occurs at 9 relocations per year, or 39 days at each production location. 
Table 3. Parameters of the Monte Carlo analysis.

\begin{tabular}{|c|c|c|}
\hline \multirow{2}{*}{ Monte Carlo Analysis parameters } & \multicolumn{2}{|c|}{ Monte Carlo parameters } \\
\hline & Average & $S D$ \\
\hline Mobile mill production volume (tonnes) & 4056 & 652 \\
\hline Number of mills (count) & 22 & 3 \\
\hline Utilization rate (\%) & $73 \%$ & $11 \%$ \\
\hline Annual relocations (count) & 9 & 1 \\
\hline Feedstock bulk density (tonne. $\mathrm{m}^{-3}$ ) & 0.17 & 0.02 \\
\hline Feedstock moisture content (\%) & $40 \%$ & $8 \%$ \\
\hline Diesel price $\left(\$ \cdot \mathrm{L}^{-1}\right)$ & $\$ 1.25$ & $\$ 0.05$ \\
\hline Labor $\left(\$ \cdot \mathrm{yr}^{-1}\right)$ & $\$ 21.70$ & $\$ 2.60$ \\
\hline Mill employees (count) & 6 & 1 \\
\hline Harvest employees (count) & 6 & 1 \\
\hline Loan rate $(\%)$ & $7 \%$ & $1 \%$ \\
\hline \% Capital as loan (\%) & $62 \%$ & $16 \%$ \\
\hline Loan term (years) & 11.30 & 1.54 \\
\hline $\mathrm{M} \& \mathrm{R}$ costs (\% capital) & $22 \%$ & $3 \%$ \\
\hline Final transport distance $(\mathrm{km})$ & 78.00 & 11.78 \\
\hline Storage cost $\left(\$ \cdot \mathrm{ft}^{-3}\right)$ & $\$ 1.12$ & $\$ 0.16$ \\
\hline Residue average load $\left(\mathrm{m}^{3} \cdot \mathrm{ha}^{-1}\right)$ & 303.72 & 25.42 \\
\hline
\end{tabular}

Table 4. Production costs of the traditional and mobile pellet mills.

\begin{tabular}{ccc}
\hline \multirow{2}{*}{ Comparison of pellet production costs by system } & \multicolumn{2}{c}{ Production costs $\left(\$ \cdot\right.$ tonne $\left.^{-1}\right)$} \\
\cline { 2 - 3 } Traditional pellet mill & Average & Standard deviation \\
Mobile pellet mill & $\$ 182.24$ & $\$ 24.47$ \\
& $\$ 402.71$ & $\$ 24.18$ \\
\hline
\end{tabular}

$\$ 182.24$ tonne $^{-1}$ in this analysis. Feedstock costs was the largest portion production costs, with labor, and capital and loan payments being the next largest contributors. The feedstock costs total $\$ 157.70 \pm 24.58$ tonne $^{-1}$ and are high in this analysis due to using comparable harvesting techniques to the mobile system. Table 5 lists the factors in the production costs. There are no generator fuel costs in the traditional pellet mill analysis because the system is connected to the provincial power grid. Equipment fuel is natural gas used to drive off feedstock moisture in the dryer. There are no final transportation costs because the analysis window ends at storage and not delivery to the end user or port. Labor costs in the pellet mill were $\$ 6.53 \pm 0.70$ tonne $^{-1}$. Maintenance and repair costs were $\$ 3.41 \pm 0.51$ tonne $^{-1}$. Storage costs include construction and are separate from capital costs to allow for clearer analysis of various scenario options. Storage costs ran $\$ 6.54 \pm 0.90$ tonne $^{-1}$. Capital and loan payments cost $\$ 6.30 \pm 0.01$ tonne $^{-1}$. 
Table 5. The breakdown of production costs for the traditional pellet mill.

\begin{tabular}{ccc}
\hline \multirow{2}{*}{ Traditional pellet mill production costs } & \multicolumn{2}{c}{ Production costs $\left(\$ \cdot\right.$ tonne $\left.^{-1}\right)$} \\
\cline { 2 - 3 } Feedstock cost & Average & $S D$ \\
Equipment fuel cost & $\$ 157.70$ & $\$ 24.58$ \\
Generator fuel cost & $\$ 0.13$ & $\$ 0.01$ \\
Electricity cost & $\$-$ & $\$-$ \\
Pellet mill labor costs & $\$ 3.27$ & $\$-$ \\
Maintenance and repair costs & $\$ 6.53$ & $\$ 0.70$ \\
Storage cost & $\$ 3.41$ & $\$ 0.51$ \\
Final transportation costs & $\$ 6.54$ & $\$ 0.90$ \\
Capital and loan payments & $\$-$ & $\$-$ \\
Equipment fuel cost & $\$ 6.30$ & $\$ 0.01$ \\
Generator fuel cost & $\$ 0.13$ & $\$ 0.01$ \\
\hline
\end{tabular}

Electricity was $\$ 3.27$ tonne $^{-1}$ and did not have any variance because the electricity use was assumed to be constant across the entire year as large industrial equipment is constantly powered. Production costs for the mobile pellet mill were $\$ 402.71 \pm 25.46$ tonne $^{-1}$. Feedstock costs were $\$ 64.89 \pm 8.72$ tonne $^{-1}$. There were no equipment fuel costs in the mobile scenario because biomass is used as the fuel for the dryer and is included in the feedstock cost. Generator fuel cost $\$ 17.87 \pm 2.17$ tonne $^{-1}$. There is no electricity cost in the base mobile pellet mill scenario because the mobile system is operating too remotely to connect to the power grid. The pellet mill labor costs were $\$ 74.63 \pm 14.04$ tonne $^{-1}$. Maintenance and repair costs were $\$ 2.79 \pm 0.61$ tonne $^{-1}$. Storage costs were $\$ 6.54 \pm 0.98$ tonne $^{-1}$. Final transportation costs were $\$ 12.58 \pm 1.74$ tonne $^{-1}$ and are the cost to transport the wood pellets to Prince George at an average distance of $78 \mathrm{~km}$. Capital and loan payments were $\$ 12.39 \pm 2.05$ tonne $^{-1}$. Table 6 shows the average cost per tonne and standard deviation of the mobile pellet mill production cost categories.

The mobile pellet mill analyzed here is most sensitive to changes in production volumes. If production volumes rise $50 \%$ to 6084 tonnes.yr ${ }^{-1}$, the cost of each tonne produced drops $\$ 38.44$, and if production falls $50 \%$ costs increase $\$ 114.26$ tonne $^{-1}$. Feedstock procurement costs and labour are the next most influential factors in production costs, with maintenance and moisture content of feedstock coming fourth and fifth. Transportation and loan variables are the least influential variables assessed here. The terms and size of the loan have a smaller impact due to the small size of capital costs compared to operating costs.

The feedstock is cheaper to be delivered in this scenario because there is significantly less transportation, less than $2 \mathrm{~km}$ in most cases versus $70 \mathrm{~km}$ in the traditional pellet mill scenario. The transportation in this scenario is more expensive than road transport because it uses a forwarder in the forests instead of a 
Table 6. The breakdown of production costs for the mobile pellet mill.

\begin{tabular}{|c|c|c|}
\hline \multirow{2}{*}{ Mobile pellet system production costs } & \multicolumn{2}{|c|}{ Production costs $\left(\$ \cdot\right.$ tonne $\left.^{-1}\right)$} \\
\hline & Average & $S D$ \\
\hline Feedstock cost & $\$ 283.60$ & $\$ 104.26$ \\
\hline Generator fuel cost & $\$ 17.17$ & $\$ 2.21$ \\
\hline Pellet mill labor costs & $\$ 74.71$ & $\$ 13.25$ \\
\hline Maintenance and repair costs & $\$ 2.77$ & $\$ 0.62$ \\
\hline Storage cost & $\$ 6.65$ & $\$ 0.98$ \\
\hline Final transportation costs & $\$ 12.73$ & $\$ 1.81$ \\
\hline Capital and loan payments & $\$ 12.29$ & $\$ 2.15$ \\
\hline
\end{tabular}

chip van on roads. The feedstock is assumed to be in the forest and not roadside, which raises the harvesting costs due to forwarders being needed and decreases production rates because the material is not in large piles next to the mobile pellet mill.

Production costs vary with the power source selected. Grid electricity is the least expensive option, and a single diesel generator powering all the equipment being the more expensive option. Grid electricity is accessible in some locations, but access is not probable. Grid electricity is included in the analysis to compare traditional pellet mills and provide a thorough analysis of available power options.

Raised storage bins are analyzed as storage in this analysis due to the practicality for loading the pellets at a future date with no active personnel in the area. The bins cost $\$ 35.31 \mathrm{~m}^{3}$ to construct and held 32 tonnes. Storage adds $\$ 55.99$ tonne ${ }^{-1}$ to production costs but allowed pellets to survive storage for more extended periods with less degradation.

Grid electricity is the cheapest source of energy for this process. The mobile system requires $323,942 \mathrm{kWh}$ each year when attached to the province's electrical grid. Industrial power in British Columbia starts at $\$ 0.12 \mathrm{kWh}^{-1}$, which is the price assumed for our analysis. This results in power costing $\$ 40,261.44$ each year, or $\$ 9.93$ tonn $^{-1}$. A dryer in an electric system requires either diesel or natural gas to burn to heat the feedstock and dry it; this results in $642 \mathrm{~m}^{3}$ of natural gas being needed at $\$ 0.11 \mathrm{~m}^{-3}$.

\section{Discussion}

Using a mobile system to produce wood pellets is more expensive than traditional pellet production. A combination of factors results in mobile pellet production being more expensive, including the small production volumes, inability to consistently access grid electricity that forces production to use more expensive fossil fuels, and remote locations. However, synergy with traditional pellet mills and government programs and objectives can help to offset the more expensive production costs. 
The mobile pellet mill has advantages over traditional pellet mill designs, including reduced transportation distances for low bulk density residues and chips and mobility when the feedstock is exhausted in an area. Transportation of feedstock is a large portion of the delivered cost of timber and residues, and any reduction in cost impacts the final price. The ability to relocate when feedstock becomes scarce, instead of requiring feedstock to come from further away, reduces the final cost of the pellets. High moisture pelletization reduces production costs by reducing the amount of energy required for drying and increasing the allowed moisture content of harvest residues.

This mobile pellet mill faces difficulty in scaling up operations. New machinery to expand production is relatively easy to drop into a traditional pellet mill. In mobile systems, expansion of production requires a new system, and new operators need training in how to operate the machinery. Identifying the locations of new feedstock locations is critical to the system's success, as setting up the system in an area with no or little feedstock available results in significant production delays.

There are several potential uses for wood pellets produced using mobile pellet mills. The first use is as supplemental production for the province's international wood pellet trade. The second is remote communities with no connection to the provincial electrical grid. The third use is in co-firing with coal fuel in power plants. Using the wood pellets to supplement the international wood pellet trade is the most likely use for the wood pellets if the producers can find methods to match current sales prices in the international market.

International trade is common for wood pellets produced in British Columbia, with over $90 \%$ of production currently exported. In this use, pellets produced from the mobile system would be trucked to a distribution site and intermixed with other wood pellets and sold on the international markets to buyers in Asia and Europe.

Remote communities in British Columbia rely on trucked shipments of diesel fuel to provide heat and power in their communities and receive a rebate on the fuel to guarantee that heat and power prices are near the provincial norm for grid-connected communities. Wood pellets produced close to these communities can offer comparable or cheaper prices for energy and provide local jobs and allow the community to become more self-sustaining.

In the co-firing application, the wood pellets are produced in the forest and shipped to a rail line to be moved to a coal power plant elsewhere in the country, likely Alberta, if it were to happen. Coal power plants only require minor retrofitting to intermix wood pellets with the coal fuel and reduce emissions. The current price of Carbon in Canada is $\$ 50$ tonne $\mathrm{CO}_{2}$-equivalent, penalizing heavy emitters to encourage emissions reductions [16]. Coal power plants employ large numbers in their local community. Finding methods to reduce emissions from these power plants while preserving employment is essential to these communities. 


\section{Conclusions}

Production costs for the mobile pelletization system are higher than in traditional systems. Feedstock costs can be lower in this system because there is significantly less transportation distance to reach the pellet mill. Mobile systems are less reliable than larger traditional pellet mills due to smaller equipment shaking and shifting during transportation and the reduced pre-treatment of feedstock to remove contaminants that damage equipment. Labour costs are comparable to a traditional system as a proportion of the production costs. Drying costs in the mobile system are less than in traditional systems because high moisture pelletization drives out additional moisture before any energy is spent on drying.

Mobile pellet mills are one answer to these environmental concerns. The smaller production scales allow producers to be more discerning in their feedstock selection, as finding feedstock for 4000 tonnes of wood pellets is much simpler than 400,000 tonnes. Currently, pellet mills are permanent, and producers invest large sums of capital in developing the mill. The scale of this investment requires that the company find any means possible to keep the pellet mill operating for the planned lifetime of the facility. A mobile system removes the need to harvest expensive feedstocks in an area when cheap feedstocks are plentiful in another area.

\section{Conflicts of Interest}

The authors declare no conflicts of interest regarding the publication of this paper.

\section{References}

[1] Sweden Power Chippers AB, Sweden Power Chippers AB-About SPC.

[2] Hiesl, P. and Benjamin, J.G. (2013) Harvesting Equipment Cycle Time and Productivity Guide for Logging Operations in Maine. Maine Agricultural and Forest Experiment Station Miscellaneous Publication, 762.

[3] Pari, L., Civitarese, V., Del Giudice, A. and Scarfone, A. (2013) Two Prototypes for Medium Rotation Forestry Harvesting. Journal of Agricultural Engineering, 44, 611614. https://doi.org/10.4081/jae.2013.363

[4] Röser, D., Mola-Yudego, B., Sikanen, L., Prinz, R., Gritten, D., Emer, B., Väätäinen, K. and Erkkilä, A. (2011) Natural Drying Treatments during Seasonal Storage of Wood for Bioenergy in Different European Locations. Biomass and Bioenergy, 35, 4238-4247. https://doi.org/10.1016/j.biombioe.2011.07.011

[5] Whalley, S., Klein, S.J.W. and Benjamin, J. (2017) Economic Analysis of Woody Biomass Supply Chain in Maine. Biomass and Bioenergy, 96, 38-49. https://doi.org/10.1016/j.biombioe.2016.10.015

[6] Perez-Verdin, G., Grebner, D.L., Sun, C., Munn, I.A., Schultz, E.B. and Matney, T.G. (2009) Woody Biomass Availability for Bioethanol Conversion in Mississippi. Biomass and Bioenergy, 33, 492-503. https://doi.org/10.1016/j.biombioe.2008.08.021

[7] Scouse, A., McConnell, T.E. and Venditti, R. (2017) Estimating the Economic Impacts Generated by Small-Scale Wood Pellet Manufacturing in Western North Carolina. Forest Products Journal, 67, 196-204. 


\section{https://doi.org/10.13073/FPJ-D-16-00035}

[8] Aksoy, B., Cullinan, H., Webster, D., Gue, K., Sukumaran, S., Eden, M. and Sammons, N. (2011) Woody Biomass and Mill Waste Utilization Opportunities in Alabama: Transportation Cost Minimization, Optimum Facility Location, Economic Feasibility, and Impact. Environmental Progress \& Sustainable Energy, 30, 720-732. https://doi.org/10.1002/ep.10501

[9] Ghaffariyan, M.R., Sessions, J. and Brown, M. (2012) Evaluating Productivity, Cost, Chip Quality and Biomass Recovery for a Mobile Chipper in Australian Roadside Chipping Operations. Journal of Forensic Sciences, 58, 530-535.

https://doi.org/10.17221/51/2012-JFS

[10] Cordoba, S. (2021) Fully Automated Wood Pellet Storage Plant. Silos Córdoba.

[11] Tumuluru, J.S. (2016) Specific Energy Consumption and Quality of Wood Pellets Produced Using High-Moisture Lodgepole Pine Grind in a Flat Die Pellet Mill. Chemical Engineering Research and Design, 110, 82-97. https://doi.org/10.1016/j.cherd.2016.04.007

[12] Sokhansanj, S. and Wright, L. (2002) Impact of Future Biorefineries on Feedstock Supply Systems. American Society of Agricultural and Biological Engineers, Chicago, 1-21.

[13] British Columbia Ministry of Forests (2005) Evaluation of Cutblock Sizes Harvested under the Forest Practices Code-1996-2002. Ministry of Forests, Forest Practices Board, Victoria.

[14] Allen, J. (2018) Naturally: Wood, Sustainable Forest Management in British Columbia.

[15] Robinson, B. (2015) Forest Legislation and Policy Reference Guide 2015. Association of BC Forest Professionals, Vancouver.

[16] Canada, Environment and Climate Change Canada (2016) Pan-Canadian Framework on Clean Growth and Climate Change: Canada's Plan to Address Climate Change and Grow the Economy. 